\title{
Attitudes Towards English at English Language Centers in Dadu District of Sindh Pakistan
}

\author{
Rukhsana Soomro* Shoukat Ali Lohar \\ English Language Development center, MUET Jamshoro Pakistan
}

\begin{abstract}
The study aimed at gaining an insight into the attitudes of students towards English. It is tried in the paper to explore the mentality of the students and the people around them, towards English language through different questions related to English language and their point of view regarding those questions. The study further explores the current position of English in the context of interior Sindh through the views of the participants pursuing language courses. The study also explores the reasons behind the expansion and popularity of English language and language centers. The motives of the students to go to learn English also explored in the study along with the role of the elite class and the state in the spread of English and the agenda of past colonial powers. The study used five questions to analyze the attitudes of the learners. The results suggested that the state and the past colonial powers have succeeded in keeping our minds colonized
\end{abstract}

Keywords: EFL, ESL, ATTITUDES, ENGLISH LANGUAGE CENTERES

DOI: $10.7176 /$ JLLL/58-04

Publication date:July $31^{\text {st }} 2019$

\section{Introduction}

This paper highlights the issue of learners' attitudes towards English in an academic/market context with a view to elaborate what people think about English and how they are inclined towards that. English in our minds, Pakistan is a third world country where people are not linguistically aware of the issues related to languages, English is expanding very rapidly making itself the dominant language of the society whether common or elite. English is a considered a symbol of competence and it has acquired prestige in our social sphere second to none. It is used as class marker. It is surrounding all the areas of our society due to the ignorance and lack of knowledge of the people about the hidden agendas behind expansion of the language. This is because we, the people of Pakistan, are dependent upon other English speaking countries, besides we are suffering from inferiority complex for our indigenous languages, which shows our slavish attitude. Those who lack English knowledge, suffer from inferiority complex (Kumar, 2011). This is because we are not only economically disadvantaged and politically backward but also linguistically handicapped (Kazmi, 2000). English as an Industry, The industry of English Language teaching is one of the fastest growing industries in the world especially in South Asia. The situation is not different in Pakistan as well, where English Language centers are a flourishing trade with every passing day. People consider English as the only available option for development, power and prestige in the society Common people including students and other professionals are highly impressed by the people who speak English and they consider English as a cornerstone of intelligence. People tend to equate the knowledge of English with knowledge itself (Zubeida Mustafa, 2010). This is not the case with only less educated or illiterate people but the so-called educated class of our country is also the victim of this superstition. This situation has led to the fast expansion of English language centers in Pakistan. Apart from the English teaching at school level students also want to learn English at Centers because it is taught as a subject at the school level not as a language. That is why we can easily and equally find language centers in the cities and far-flung areas of the country as well. In almost every part of the country, whether town or cities, there can be seen hundreds of advertisement boards, banners or hoardings from the English Language centers or schools claiming to be English medium attracting a huge chunk of the folk. They are in areas ranging from the most affluent and posh communities of the elite class to the slums and even in rural areas.

It is a far cry from the rolling green grounds of Aitchison College in Lahore to a two-room house in a slum which advertises itself as the 'Oxford and Cambridge Islamic English medium School' (Rahman, 1997).

English is deemed necessary for our existence in and keeping pace with the modern world as it is considered a tool for survival. Parents want their children to study in English medium schools from the very beginning irrespective of the social class they belong to. Apart from sending their children toEnglish medium schools, they also pour money from their pockets into the English Language Centers by forcing their children to attend those centers for making them more efficient the language

\section{2 "English": a language or the language?}

Anjum (2000) suggests that English has become a pattern of life and its cultural influence continues to be strong. English is considered more than a language in Pakistan. It is not thought of as a language; rather it is considered as the language. This is the situation because we have been the slaves of the British and our country has 
remained the colony of the British Empire, which has resulted in our blind attitudes towards English. Our current scenario is very much in similarity with that of the Colonial Kenya where the language was imposed on its inhabitants as the only language superior to all. Famous Kenyan writer Ngugi wa Thiongo, in his book "Decolonizing the Mind", has marvelously portrayed the image of the situation. In Kenya (during colonial era), English became more than a language: it was the language and all the others had to bow before it in defense. Any achievement in spoken or written English was highly rewarded; nobody could pass the examination who failed the English language paper no matter how brilliantly he had done in the other subjects (Ngugi, 1986).

Nowadays, after passage of several decades of colonization, we are still under the influence of English and perceive it as only respectable language thinking of other languages as inferior and the speakers of other languages as incompetent. We are no more physically colonized but mentally we are still colonized and Ngugi also wants us to decolonize our minds through his writings. Colonization of the mind occurs because of the domination of the colonizer's language over the language of the colonized (Tsuda, 4). The dominance of English also creates the prejudices and stereotypes, which, in turn, create discrimination against those who do not or cannot speak English. For example, those who cannot speak English fluently are labeled as incompetent and thus insulted and perceived to be inferior (Yukio Tsuda, 2008). Being able to speak English is such a source of pride for the people in our country that some proficient speakers of English are inclined to insult and discriminate against those who cannot speak English. "English, because of its dominant prestigious status, functions as a basis of discrimination, and therefore legitimates and reproduces the perceptions of linguistic prejudice and discrimination" (Ibid, 4). People who can speak English are placed at the top level of the social hierarchy while those who do not or cannot are placed at the bottom.

\subsection{Purpose of the study and Research Questions:}

The language attitude is a very common issue which has penetrated in the minds of the people which needs to be explored. The main purpose of the study is to get an insight into the attitudes of the people especially students about English language, its importance and place in the society. What they think of the language in this era of the "globalization" and how it determines their attitudes. Some potential questions of the study, which the researcher wants to explore, are as follows.

What do the students think about English Language?

What is the reason behind their thinking?

The study conducted in a major city of central Sindh on a small scale. It is tried to stick to a particular level of students during the study. The participants are the students of advanced level at two English Language Centers in the city. Advanced level students are selected because they are perceived to have a better understanding of the language and their ideas might be shaped accordingly.

\section{Literature Review}

Attitude can be defined as a set of beliefs developed in a due course of time in a given socio- cultural setting. Although it necessarily does not determine behavior but can have some impact on it (Verma, 2005). Attitude refers to "a hypothetical construct used to explain the direction and persistence of human behavior" (Baker, 1992). In other words, it can represent internal thoughts, feelings and tendencies in behavior across a variety of contexts. Although an attitude is individual, it has origins in collective behavior. Moreover, some characteristics of attitude are: it is learnt, it is not inherited, it is also likely to be relatively stable, and it has a tendency to persist. Attitudes also play a vital role in language growth or decay, restoration or destruction. In other words, the status and importance of a language in society and within an individual can be adopted and taught (Baker, 1988). In the life of a language, attitudes to that language appear to be important in language restoration, preservation, decay or death (Baker, 1992).

Crystal (1992) states that, language attitudes are the feelings people have about their own language or the languages of others. According to Gardner attitude has:

"Cognitive, affective and co native components and consists, in broad terms, of an underlying psychological predisposition to act or to influence behavior in a certain way. Attitude is thus linked to a person's values and beliefs and promotes or discourages the choices made in all realms of activity, whether academic or informal." (Gardner, 1985)

In second/foreign language learning two social psychological variables - attitude and motivation - play the key role. Gardner suggests that when studying language attitudes, the concept of motives is important. In the language learning context, motivation (to learn the language) refers to the combination of effort plus the desire to achieve the goal of learning the language plus favorable attitudes toward learning the language (Gardner, 1985). The term 'motivation' means 'referring to the extent to which the individual works or strives to learn the language because of a desire to do so and the satisfaction experienced in this activity (ibid, 1). Gardner highlights two different kinds of motivation in second language learning situation:

i) Instrumental motivation - When the learner wants to learn a language to fulfill immediate goals, such as 
getting a job or passing an examination etc., his/her motivation is of instrumental kind.

ii) Integrative motivation - when the motive to learn a language is to communicate and integrate with people from another culture who speak the same language, it is called integrative motivation.

Our attitude towards the language determines the tendency or reluctance to learn that language. In our linguistic setting which is developed by the society, English shapes the behavior of the people and students in particular. People who are proficient in English tend to think that they are superior to those who are not and they think that in order to become successful it is necessary for them to learn English. Meenakshi (2005) has highlighted that Proficiency in English Language can only make you successful - this is the belief spreading all over giving rise to the study of the learners' attitudes from the grass root level.

Kim (2002), while examining the perception and attitudes towards English in East and South East Asia, maintains that learners of English tend to look at it as a 'magic wand': they perceive English to have magical powers that makes it all happen as in fairy tales. These perceptions of English are well reflected in national policies of most countries teaching English to a point where the promotion of English is done at the cost of native languages as Tariq Rahman (2010) also reports about Pakistan: "from the earliest days in Pakistan the state seems to have followed discrepant policies about English. The covert policy, or rather the practice, was to allow English to continue as an official language regardless of what the constitution might have declared." Being able to speak English is also perceived as such a source of pride for the people in Pakistan that some proficient speakers of English are inclined to insult and discriminate against those who cannot speak English as Yukio Tsuda (2008) puts forward "English, because of its dominant prestigious status, functions as a basis of discrimination, and therefore legitimates and reproduces the perceptions of linguistic prejudice and discrimination". This discrimination extends to such an extent that people who can speak English is placed at the top level of the social hierarchy while those who do not or cannot placed at the bottom. Another factor, which determines the attitudes towards English in Pakistani context, is colonization, as Annika (2003) reports that it is a fact that English has spread because of exploitation and colonization. The languages of the colonizing nations are crucial to the domination of the mental universe of the colonized (Ngugi, 1981). It is notable that, especially in many ex-colonies of Britain, English is still the language of exclusive social elite and it determines the attitudes of the people in general. Moreover, Rahman (2009) states that the members of this elite had a stake in the continuation of English because it differentiated them from the masses; gave them a competitive edge over those with indigenous languages or traditional madarassa education; and, above all was the kind of cultural capital which had snob value and class-identity marker. It is a reality that in the Pakistani context a person who speaks English is considered intelligent and having knowledge, and most of the so-called educated people are not the exception, even the teachers in the academic institutions prefer those students who are proficient in English. Those who lack English knowledge suffer from inferiority complex. They should realize English is not equivalent to intelligence (Kumar, 2011). This type of attitude is the reflection of Lord Macaulay's plan of shaping the attitude of Indians towards English and its speakers. Macaulay wanted to produce a class of people, Indians in blood and color, but English in taste, in opinion, in morals - that is, with an entirely changed chemistry and bio-rhythms (Baumgardner, 2000). People do not have an aesthetic aspect of English in their minds; they do not like English because they love it but want to learn it because they are impressed by people who speak English and the power they possess, as reported by Anjum (2000) that English in Pakistan is more the language of Macaulay than of Shakespeare.

Although English has faced some resistance by certain intellectuals as Gandhi considered English to be an alien language and thought that keeping it would mark subcontinent's continued slavery (Crystal, 2003). There were movements to remove English, such as (Angrezi Hatao Andolan), yet the common people's as well as the elite's and the State's attitude towards English has always been very favorable, as Rahman (2010) states "English is an elitist preserve and even if the national language (s) is supported by a minority, that support is weak. As far as the state itself, its stated policy is to support the national language (s) but this support is only to keep up appearances. It is, at best only rhetorical. Powerful sections of the Westernized, dominant, urban, elite, corporate giants, upper bureaucracy, officer corps of the armed forces, higher judiciary, articulate and visible sections of the academia and the intelligentsia - are actually not at all resistant to English, they enthusiastically accepting towards it." Hence, the movements against English are often emotionally charged but tend to quickly run out of steam (Rahman, 2006).

This approach of the State and other institutions has also contributed in shaping the attitudes of students towards English and in its expansion. Sabiha Mansoor (2009) conducted a research on students' attitudes towards English. Her study shows that a language spread in English is due to the highly positive attitudes towards English as an "international language", displayed by the students and teachers. The students showed a strong desire to study English as a medium of instruction and as a compulsory subject for mainly instruments reasons. 


\section{Methodology}

The study based on the qualitative approach of research. The researcher has focused on the narrative data to extract the underlying beliefs of the students towards English language. Qualitative approach involves the collection of extensive narrative data in order to gain insights into the phenomenon of interest; the rationale behind the use of qualitative research is to understand the context of the attitude. Qualitative research is not just concerned with describing the way things are but also extracting insight into how the things got to be the way they are.

Context of the study The study was carried out at two English language centers in Dadu district of central Sindh, Pakistan. Total number of participant for the study was twenty. Ten students from each centre, pursuing their language course in advance level, were selected as sample of the study to fill in the questionnaire. The students were selected randomly from the classes to ensure participation of students with different mindset. The participants were studying in those centers for more than six months and their ages ranged from 15 to 25 years. The number of female participants was too low as compared to male participants. In one of the centers there were 15 male students and only 2 female students while in the other there was only one female student out of 16 students present in the class. Most of the students spoke two or three languages including English. Majority of the students had previously studied/were studying in government schools/colleges. The selected centers are perceived to be well established and offering quality courses in English. One of the centers was offering three levels i.e. beginning, middle and advance, language certification course, each level consisting of three months while the other was offering 6 months "full" language course and its administrator was of the opinion that 6 months is quite sufficient time to learn a foreign language although the observation of the researcher was quite contrary to that. The selected participants were the students of advance level. The reason for selecting advance level students was that they were perceived to be mature and could respond in an appropriate manner. The students were sitting in the class in arranged manner while conducting the study To examine the attitudes of the students towards English, the study was carried out through face-to-face meeting with the participants in the centers where they were studying. The data collection tool was an open-ended questionnaire consisting of five questions. The questions were written in easily understandable language. Each question was specifically designed to gain insight into the attitudes of the students towards English language. The students were not told about the purpose of conducting the study. They were only told to fill in the questionnaire with their opinion The questions in the questionnaire were designed to know the attitude of the participants and people around them about English language. The first question was about the motive behind joining the English language centers, which was intended to know about the main motivational force behind certain attitudes of the participants. First question was about the personal priorities of the participants; while the second question asked about the attitude of people around the participant, i.e. family and friends. The third question was about their own attitude towards the students who are good in English language. That question was assumed to know about their inner feeling about the students, because English creates some kind of sense of superiority. The fourth question was about the expansion and popularity of English language centers. It was to know about their thoughts regarding the causes of the popularity of expansion of English and English Language centers. It is considered in the context of research that the people who know English are intelligent, a person speaking good English is respected in our society, for instance the drama serial "Choti Si Dunia" was based on Sindhi society where Janu German is considered more intelligent than Murad Ali Khan who speaks slow English, so the last question of the research was also designed to know the feeling of students who speak English fluently. The participants were explained each question in English and in their mother tongue also. The questionnaire comprised of two pages, after each question free space was provided to write their opinion about the question. The participant were told to ask explanation of the questions wherever they felt need. They were asked to write their opinion as long as they could in the provided space for each question. After the data collection process the questionnaire were closely scrutinized to get some ideas about the attitudes of the participants regarding English language. When data was analyzed closely, some themes emerged from the views of thee participants. The emerging themes, according to the participants' views, are discussed in this portion of the document. 


\section{Table one}

\section{Emerging themes}

The main themes extracted from the responses of the participants are discussed below

- Employment

8 respondents out of 20 described English as the necessary tool to get a job in Pakistan, so they were also learning for the same purpose.

- International communication (Lingua Franca)

Many of the students described their purpose by describing English as the language of communication with other countries of the world.

- Higher education

Many respondents described "access to higher education" as the main motivation for learning English. According to them all the books are written in English, if they do not learn English, they will fail short of their aims.

Gaining knowledge

Some respondents narrated that they were learning English to gain knowledge.

- Progress and success

Some students expressed the wish that by learning English they would get success and that is the way to progress in the society.

- Prestige

One of the respondents stated about his wish of leaning English to get respect, prestige and status in the society.

\section{Table two}

\section{Emerging themes}

$$
\text { Pride }
$$

6 respondents described feelings of in a way that their family and friends are proud of them, while they are learning English.

- Encouragement and appreciation

Many of the respondents get appreciation and encouragement from their friends and family members.

\section{Impression}

Three students replied with the impression that their family and friends are

Impressed from them due to their English learning

\section{Table 3}

\section{Emerging themes}

- Satisfaction

The respondents were satisfied about the future of those students who were good in English; according to them they would achieve their aim of life easily.

- Protective feelings

Six students expressed their feeling that they feel jealous about the students who are good in English. They wish to compete with them.

- Stimulation

Some of the students described that the students are source of inspiration for them that they are stimulated to be like them. 
Table four

\section{Emerging themes}

- Competition

Many of the students were of the opinion that English language centers are quite necessary and popular because there is a "competition" about English language in Pakistani society; everyone wants to learn English to compete in the society.

- Business

One of the students was also of the opinion that it has become a business to run a language center.

- $\quad$ Serving the nation

A few of the students were also of the opinion that these language centers are serving the nation by expanding the teaching of English language.

- Necessity

The main theme of the responses was the opinion that these centers are necessary for the modern world. The need of modern world compels them to join these language centers.

- $\quad$ Some students described their opinion that these language centers are very good place to remove hesitation and for practice, so they join these institutes

Some of the students explain the popularity of the centers that these centers provide atmosphere of learning the language, which cannot be practiced at home or school.

Table five

Emerging themes

- Intelligence

Some students considered the people who speak English as intelligent, one of these students wrote that

"Pakistan will progress due to the people who speak fluent English.

- Success

Some of the students also expressed that those who speak fluent English will succeed in their life.

- Jealousy

Some respondents expressed in their response that they feel jealous when someone speaks English fluently. The highest number of students (11) expressed their wish to be like them.

Data analysis: The first thing that was analyzed was, the students could not express themselves in an explicit and categorical manner. It was observed that in spite of selecting advance level students from the language centers as samples of the study, common grammatical mistakes were found in a huge amount. Not even a single questionnaire was observed free of grammatical mistakes. Students mostly used past tense instead of present tense to express their opinion about different question. In many responses the use of present continuous and past continuous, where it was not required, was also observed.

Another common thing which the researcher found in the questionnaire was that the participants did not use articles where they were required in their text or even if they were used, they did not make sense. It seemed as if most of the participants did not know the use of the articles which is supposed to be an easy component of grammar and is taught at very basic level in English language centers. Most of the participants used 'a' in place of 'the' and vice versa. The research found many instances of misspellings in every response written in the provided questionnaire. Some instances of misspellings like 'embestor' instead of 'ambassador' were also found.

The research was conducted in a multilingual context $\mathrm{w}$ where most of the participants were Urdu or Sindhi speaking. Another thing in this context was that the researcher found some Urdu words written in Roman English in an English discourse, like, "my chachu and phupho", which stands for "my uncle and aunt". Most of the responses were not written in coherent and cohesive sequence, the respondent stranded from here and there during responding the questions in the paper. A little number of responses was observed coherent and cohesive and the researched came across some difficulties in extracting the theme because of these factors.

The use of the word 'very' was found common in most of the responses. When the students wrote about English or its importance they frequently used the 'very' to enhance the importance of the language. Some other adjectives and stereotypes like 'an international language'; 'important', 'good' were also used very frequently by the participants. The respondents showed their interest comparatively more in first and last question which were:

i. What is your purpose for learning English?

ii. How do you feel when you listen to someone speaking English fluently?

These were questions in which the respondents expressed their views in detailed and long expression.

In response of all the questions the researcher observed that the participants had inclination and strongly favorable towards English language. Almost all the participants were found in craze of English and they expressed their strong desire to learn English.

There was a question which attracted the attention of the students more than other questions. Most of the participants responded that their purpose for learning English was to get good jobs; others responded that they 
wanted to be successful in their life and English was necessary for them to achieve their aim, however, they had their own parameters for 'success' and 'aim'. Gaining knowledge was also mentioned in many responses in which it was argued that almost all the text books are written in English and if they were not proficient in English it would be very difficult for them to gain knowledge. The researcher observed that the most number of the participants were of the opinion that English is an "international language" and they deemed it necessary for development. Some participants expressed that they wanted to learn English for higher education or going abroad but their ratio was very low. In the response of this second question the researcher found that most of the participants were appreciated by their friends and family on learning English. Participants responded that they had been encouraged by their friend and family for learning English and such appreciation had not been received before joining English language centers. Six participants responded that their parents felt proud because their children were learning English and they boasted to others that their children were going to English language centers. Some others responded that their friends were impressed from them after they joined English language centers and started speaking little English. question was also designed to gain an insight into the attitudes of the participants. The analysis of the responses of this question showed that the participants linked the success with those who were good in English. Most of the participants seemed impressed by those who were good in English and considered them intelligent. An interesting factor in the response of this question was observed by the researcher in that six participants expressed their jealousy and protective feelings regarding those who were good in English. This showed a very high regard for English in their minds. While some other participants expressed that they were inspired and stimulated by those who were good in English and they also wanted to learn English like them. A great number of participants thought that popularity of English language centers was because the people think of them as necessary. The participants responded that it was necessary for the students to go to the centers to learn the language. This was the main theme of the responses of this question, however, some respondents were found having the opinion that English centers are necessary because there is competition about English language in Pakistan. It was analyzed from some of the responses that language centers are serving that nation through teaching English language. Six participants believed that English language centers are popular because they remove the hesitation of the students and develop confidence in them. Another factor expressed by them was that they did not have suitable environment in schools or colleges, therefore English language centers are attracting a great number of students. There was only one student who believed the English language centers are popular and spreading because it was growing business. The analysis of the responses of this question showed that the highest number of students (11) expressed their wish to be like them. They showed their strong desire to speak fluently like them at any cost. Many participants thought the fluency in speaking English is the sign of intelligence. Some respondents expressed that they feel jealous when someone speaks English fluently, while some believed that those who speak English fluently are successful people.

\section{Results and Discussion:}

The explains the responses obtained from the participants and the discussion emerging from that. An open ended questionnaire was used as an instrument for the research which helped in gaining insight into the attitudes of the participants. The questionnaire was administered to obtain narrative data from the respondents. The responses of the questionnaire discussed below. The researcher had the hypothesis was that the students think of English as necessary for them and take it more than a language and the results of the questionnaire support this hypothesis.

\section{Findings}

It was found in the study that students had a very favorable attitude towards English language and they think that English is the solution of their problems. An interesting thing which the researcher came across during the research was that, when the researcher introduced himself to the participants, gave questionnaires to them and explained them to fill in the questionnaire, he used English, and meanwhile, the participants were very attentive and seemed very much impressed from but as soon as he switched to local language, the participants seemed very relaxed and started making noise. It showed that when someone spoke English to them, they took it very serious and if the same thing was explained in local language, it did not leave an impression on them. Throughout the study, the participants never showed their unfavorable attitude towards English.

\section{Limitations of the study}

This is a limited study on the attitudes of the students toward English language on a very small scale and a very minute effort in this area, which requires research on a very large scale. Due to different constraints and my minute comprehension of the phenomenon, some shortcomings may be observed in the study.

\section{References}

Anjum R Haque, (2000). The position of English in Pakistan, (in) The English Language in Pakistan, Alpha Sky Printers, Rawalpindi 
Annika, H, (2003). English in India: loyalty and attitude, LANGUAGE IN INDIA, Strengths for Today and Bright Hope for Tomorrow, vol: 3

Baker, C. (1992).Attitudes and Language, Avon: Clevendon.

Baker, C (1988). Key Issues in Bilingualism and Bilingual Education, Clevedon: Multilingual Matters.

Crystal, D (1992).An Encyclopedic Dictionary of Language and Languages, Cambridge, MA: Blackwell.

Gardner, R. C. (1985). Social Psychology and Second Language Learning: The Role of Attitude and Motivation

Kumar, N (2011). English is no measure of intelligence, Times of India, February 20, 2011.

Kazmi, Yadullah (2000) Hidden Political Agenda behind Teaching English as a Second Language, IIUM Research Management Center, London: Edward Arnold

Meenakshi (2005) Learner's Attitude and Its Impact on Language Learning, Invertis Institute of Engineering \& Technology, Bareilly 243123 (Uttar Pradesh) India

Kim, Y. S. (2007) Korean adults' attitudes toward varieties of English, The University of Edinburgh.

Mustafa, Zubaida (2011) English as a barrier, The Dawn, April 20, 2011.

Ngugi wa Thiongo (1981). Decolonizing the Mind: The politics of language in African Literature, London: James Carey.

Phillipson, R (2009). Disciplines of English and disciplining by English, Asian EFL Journal (electronic)

Rahman, T (2010).Language Policy, Identity, and Religion: Aspects of the Civilization of the Muslims of Pakistan and North India, Chair on Quaid e Azam \& Freedom Movement, National Institute of Pakistan Studies, Quaid-e-Azam University, Islamabad Rahman, T, (2009).Language Policy, Language Death and Vitality in Pakistan, Oxford University Press, New York

Rahman, Tariq (1997) English-Teaching Institutions in Pakistan, Oxford University Press

Baumgardner, Robert J, (2000). The English Language in Pakistan, Alpha Sky Printers, Rawalpindi

Crystal, D (2003) English as Global Language, , Cambridge University Press

Rahman, T (2006). Language and Politics in Pakistan, Oxford University Press,

Sabiha, M (2009). Regional languages of Pakistan: Issues and Concerns for language planning in Higher Education, Oxford University Press, New York

Tsuda, Y, (1998). The Hegemony of English and Strategies for Linguistic Pluralism: Proposing the Ecology of Language Paradigm, Nagoya University, Aichi, 464-01, JAPAN 